\title{
РАЗВИТИЕ ПРОФЕССИОНАЛЬНЫХ КОМПЕТЕНЦИЙ МОЛОДЫХ ПЕДАГОГОВ В УСЛОВИЯХ СЕЛЬСКОЙ ШКОЛЫ
}

\section{DEVELOPMENT OF PROFESSIONAL COMPETENCIES OF YOUNG TEACHERS IN THE CONDITIONS OF A RURAL SCHOOL \\ G. Bayagantaev A. Ivanova}

Summary: At present, a rural school, more precisely, rural educational organizations / institutions operating in rural areas, are included in the municipal networks of educational institutions, they are a subsystem of the Russian education system. The training of rural teachers takes place in the context of a multilevel system of pedagogical education (higher and secondary vocational) and the variability of additional education for teachers. The modern system of continuous pedagogical education in Russia includes the stages of pre-professional, vocational (secondary and higher), postgraduate education at various levels, various types of additional pedagogical education; formal, non-formal and informal types of continuing education of teaching staff. The main condition for the formation and development of a competent teacher is the development of professional competencies. In this article, the author has made an attempt at scientific analysis and critical understanding of the development of professional competencies of young teachers in a rural school.

Keywords: development of professional competencies, the formation of young teachers, rural educational institutions, continuing education of a teacher.
Баягантаев Григорий Григорьевич

Аспирант, ФГАОУ ВО «Северо-Восточный федеральный университет им. М.К. Аммосова», г. Якутск Grigorib82@yandex.ru

Иванова Августина Васильевна

Д.n.н., профессор, ФГАОУВО «Северо-Восточный федеральный университет им. М.К. Аммосова», г. Якутск

Аннотация: В настоящее время, сельская школа, точнее, сельские общеобразовательные организации/учреждения, функционирующие в сельской местности, входят в муниципальные сети образовательных учреждений, являются подсистемой системы образования России. Подготовка сельских учителей происходит в условиях разноуровневой системы педагогического образования (высшего и среднего профессионального) и вариативности дополнительного образования педагогов. Современная система непрерывного педагогического образования в России включает этапы предпрофессионального, профессионального (среднего и высшего), постдипломного образования разных уровней, различные виды педагогического образования; формальное, неформальное и информальное виды непрерывного образования педагогических кадров. Главным условием становления и развития грамотного педагога, является развитие профессиональных компетенций. В настоящей статье автором предпринята попытка научного анализа и критического осмысления развития профессиональных компетенций молодых педагогов в условиях сельской школы.

Ключевые слова: развитие профессиональных компетенций, становление молодых педагогов, сельские образовательные учреждения, непрерывное образование педагога.
$\mathrm{B}$ системе непрерывного образования педагогов появились «альтернативные игроки» - конкурирующие друг с другом государственные и негосударственные структуры. Инициативу организации непрерывного образования педагогов берут на себя общественные профессиональные педагогические движения и сообщества, в том числе педагогов сельской школы. Мощнейшим конкурентом традиционной системе непрерывного педагогического образования выступает Интернет с его неограниченными возможностями предоставления образовательных услуг для разных категорий педагогических работников, включая сельских учителей. [12, с. 22]

Обобщающей характеристикой современного этапа следует признать диверсификацию непрерывного образования сельских учителей при отсутствии легализации (нормативно-правового обеспечения) целенаправленного непрерывного образования учителей современной сельской школы.
Подчеркнём, что концепции и состоявшиеся стратегические программы повлияли на все элементы - уровни и сегменты системы, в том числе на систему образования в сельской местности страны, на сельскую школу и сельского учителя; способствовали разработке и запуску концепций, стратегических и тактических программ, планов, «дорожных карт» во всех субъектах РФ, конкретизировавших реализацию целей и задач, определённых федеральными документами, в преобразованиях системы образования конкретного региона. [6, с. 33]

Таким образом, последние десятилетия были насыщены значительными комплексными изменениями российского образования в целом и каждого сегмента системы в частности.

Объективности ради надо отметить, что политика реформирования образования в сельской местности страны имеет как негативные, так и позитивные последствия. Развернувшаяся во всех регионах и территориях 
России реализация приоритетных национальных проектов (2005-2012г.), мероприятий образовательной инициативы «Наша новая школа» (2009г.), программ модернизации общего образования (2011-2017г.), Приоритетных национальных проектов (с 2018 г по настоящее время) способствовала определённым позитивным изменениям социокультурной образовательной ситуации в российской провинции. [14, с. 39]

Во-первых, это усиление социальной направленности образования, предопределяющей ему не только образовательные, но и социокультурные, социальнопедагогические функции; расширение доступности дошкольного и дополнительного образования; реализацию программ патриотического, физического воспитания и оздоровления детей, подростков, молодёжи; комплексные меры социальной поддержки различных групп населения, оказавшихся в трудной жизненной ситуации, детей с проблемами развития и ограниченными возможностями здоровья.

Во-вторых, внедрение в образовательную практику федеральных стандартов образования, в соответствии с которыми сельские образовательные организации: включают в образовательную программу новое содержание, современные технологии, разнообразную познавательную и социально значимую деятельность обучающихся; привлекают к управлению учреждением родителей и общественность территории, создают комфортные условия для обучения разных категорий обучающихся. Доступность Интернет, обеспечение соответствующим оборудованием и компьютерными программами позволяют сельским школьникам дистанционно обучаться и получать образовательные услуги.

В-третьих, произошло определённое улучшение в обеспечении доступности образования и условий образовательного процесса. Приобретено новое учебное оборудование и мебель, произведены ремонты значительного количества учреждений, в том числе затратные - ремонт крыш, замена окон, реконструкция спортивных залов и др. Школьные автобусы используются для доставки детей в образовательные и культурно-досуговые центры, школьные столовые с современным оборудованием обеспечивают детей качественным питанием.

Совокупность позитивных изменений в образовательной политике способствует социальной мобильности выпускников сельских школ.

Однако продолжающаяся реализация организационно-экономической модели развития отрасли приводит к распространению отрицательных социальных явлений, крайнее из которых - закрытие, прежде всего, сельских малочисленных малокомплектных школ.
Разрушаются базовые социальные институты села: сельская семья и сельская община, сообщества, что способствует распространению детского неблагополучия. Ежедневный подвоз детей ведёт к физическим перегрузкам, имеет определённые негативные психологические последствия, связанные с адаптацией, с неполноценностью пребывания в новом детском коллективе: в связи с необходимостью переездов дети практически исключены из внеурочной работы школы и системы образования. [2, с. 70]

Отрицательными последствиями проживания детей из отдаленных населенных пунктов в интернатах является отчуждение ребёнка от семьи, а в отсутствии родительского пригляда - искусственно созданное социальное сиротство, рост агрессивного поведения детей, детской и подростковой преступности, распространение алкоголизма и наркомании среди подростков. Недооценка и/или игнорирование социальных эффектов административной модели модернизации образования оказывают негативное влияние на все без исключения социальные институты села.

Как мы уже отмечали, для становления педагога сельской школы как специалиста высокого уровня, необходимо проведение постоянной работы по развитию профессиональных компетенций молодых педагогов в условиях сельской школы.

В настоящей статье говорится именно о «формировании» профессиональных компетенций, поскольку речь идет о сознательно управляемом процессе с заданной целью - довести его до задуманного уровня, применяя определенные методы и технологии и создавая необходимые условия. Формирование можно рассматривать и как результат развития (процесс и результат количественных и качественных изменений человека, связанные с постоянными, непрекращающимися изменениями, переходами из одного состояния в другое), и как организаторскую деятельность педагога (педагогического коллектива) по обучению и воспитанию обучающихся.

Формирование профессиональных компетенций молодых педагогов в условиях сельской школы является процессом, который предполагает постепенное целостное становление профессионального работника с высоким уровнем развития профессиональных компетенций: информационной, исследовательской, коммуникативной, организационно-управленческой и компетенцией самоорганизации и саморазвития. [5, с. 88]

Данный процесс представляется как процесс наращивания (развития) нового профессионального качества педагога (педагог со сформированными профессиональными компетенциями), который ранее целенаправленно не осуществлялся, берет свое начало 
во время педагогического образования и продолжается в профессиональной деятельности педагога, имеет уровни сформированности, свидетельствующие об определенной степени владения компетенциями.

Модель формирования кластера профессиональных компетенций у педагогов системы сельского образования детей включает в себя концептуально-целевой, содержательный, организационно-технологический и оценочно-результативный блоки. Их структурное и содержательное наполнение детерминировано тремя значимыми для конечной цели нашего исследования причинами.

Первая - это потребность общества в гибких, мобильных, конкурентоспособных специалистах, способных к самообразованию на протяжении всей жизни. Образовательный процесс необходимо выводить на новый уровень интеграции, уходить от предметоцентризма, выстраивать такое содержание образования, где гармонично взаимодействуют профильность и метапредметность. Именно надстройка «мета» позволит человеку, получив профессию, гибко и качественно реагировать на «вызовы» в профессиональной деятельности и за ее пределами, «пересобирать» свои ЗУНы в формат, актуальный здесь и сейчас. Вторая - это переход системы образования на компетентностный формат подготовки кадров. В качестве результата образования выступают различные наборы компетенций, что позволяет учитывать особенности сфер и профилей деятельности и организации процесса формирования компетенций. Третья государственный и социальный заказ на педагогических работников с новым педагогическим мышлением, со сформированными профессиональными компетенциями. $[9$, с. 49]

Каждый из представленных факторов нашел свое отражение в процессе моделирования процесса формирования профессиональных компетенций педагога сельской школы.

Рассмотрим более подробно компоненты модели.

Концептуально-целевой блок модели раскрывает методологическую основу процесса формирования профессиональных компетенций в виде интегративного, компетентностного и профессионального подходов, целевые установки стратегического и тактического уровней, а также включает выявленные и обоснованные нами профессиональные принципы, лежащие в основе рассматриваемого процесса.

Мы говорим о взаимодополнении компетентностного и профессионального подходов в процессе формирования профессиональных компетенций у педагогов сельской школы.
Компетентностный подход предъявляет требования к образовательному результату, способности и готовности педагога действовать в процессе профессиональной деятельности, а метапредметный - дополняет содержание подготовки педагога требованиями универсальных способов деятельности, отвечающих за междисциплинарные, надпредметные умения и навыки.

Особенно значимым для нас является вывод о том, что основным непосредственным результатом образовательной деятельности становится формирование профессиональных компетенций.

Стратегическая цель формирования профессиональных компетенций - обеспечить высокий уровень сформированности профессиональных компетенций у педагогов, позволяющий им достигать профессиональных результатов в своей профессиональной педагогической деятельности и формировать профессиональные компетенции у обучающихся. Тактическая цель - обеспечить процесс формирования профессиональных компетенций организационно-педагогическими условиями. $[13$, с. 51$]$

Таким образом, подходы, принципы и цели, представленные в концептуально-целевом блоке нашей модели, являются основой для построения содержательного компонента процесса формирования профессиональных компетенций.

Содержательный блок модели описывает то, что подлежит формированию и раскрывает наполнение профессиональных компетенций: информационной, исследовательской, коммуникативной, организационноуправленческой, самоорганизации и саморазвития.

Когнитивный компонент профессиональных компетенций отвечает за получение совокупности метазнаний, на основе которых педагог сможет эффективно работать с информацией, проводить исследование, взаимодействовать с окружающими, организовывать и управлять, заниматься саморазвитием.

В структуре профессиональных компетенций педагога сельской школы система метазнаний (информационных, исследовательских, коммуникативных, организационно-управленческих, самоорганизации и саморазвития) помогает ему действовать в нестандартных и нетипичных ситуациях, реагировать на изменения, решать разные задачи в работе с детьми.

Эти метазнания позволяют педагогу решать профессиональные надпредметные, межпредметные, полисферные задачи в сфере ДОД, то есть демонстрировать сформированность метаумений - поведенческий компонент профессиональных компетенций. 
Мотивационно-ценностный компонент профессиональных компетенций состоит из параметров, касающихся личностного отношения педагога к смыслу и значению профессиональных результатов образования, понимания важности формирования профессиональных компетенций и у педагогов, и у обучающихся в сфере сельского образования. [4, с. 83]

Профессиональные категории педагогического образования - это ключевые сущности, узловые точки, благодаря которым конструируется комплексное знание педагогической области; это такие категории, понимание которых не относится к какой-то конкретной дисциплине, а являются сквозными на протяжении всего педагогического образования (например, образование, система, качество, педагогический процесс, педагогические технологии и др.). Профессиональные категории являются сквозными на протяжении всего периода освоения образовательной программы: через циклы, модули, практики, научно-исследовательскую работу, внеучебные активности.

Многоуровневая система профессиональных фундаментальных категорий постепенно раскрывается для обучающихся от дисциплины к дисциплине, путем изучения различных сторон обозначенных категорий, путем последовательного наполнения знаний о них, формирования умений и навыков их практического применения.

Достижение указанного результата происходит в образовательном пространстве посредством организации процесса обучения педагогов в рамках конкретных образовательных программ. Их тщательное изучение позволило нам констатировать факт наличия профессионального компонента в дисциплинах учебного плана -это смысловые, сущностные дидактические единицы предмета, обладающие метапредметным свойством полифункциональности и способствующие получению метазнаний, формированию метаумений и мотивационно-ценностных ориентаций. Выявление таких профессиональных компонентов в преподаваемых предметах расширяет возможности учебного процесса, наполняя его профессиональным содержанием. [1, с. 44]

Именно метазнания, метаумения и мотивационноценностное отношение являются основой содержания процесса формирования профессиональных компетенций.

Далее необходимо представить организацию этой деятельности.

Организационно-технологический блок раскрывает процессуальную сторону изучаемой проблемы и включает этапы формирования профессиональных компетенций, организационно-педагогические условия, пе- дагогические технологии формирования компетенций.

Высокий уровень сформированности профессиональных компетенций может быть достигнут в том случае, если в образовательном процессе будет реализован комплекс организационно-педагогических условий. В нашем исследовании мы делаем упор на три условия, речь о которых пойдет далее. На наш взгляд, это необходимые условия. Кроме того, можно выделить и ряд других организационно-педагогических условий, которые будут достаточными в процессе формирования профессиональных компетенций у педагогов сельской школы. Эти условия, безусловно, являются важными и желательными в исследуемом процессе, но тем не менее имеют второстепенное значение по отношению к условиям, которые реализовали мы в своем опыте. Все условия определены на основе изучения особенностей формирования профессиональных компетенций у педагогов в ходе организации опытно-экспериментальной работы.

К достаточным организационно-педагогическим условиям формирования профессиональных компетенций у педагогов сельской школы можно отнести: [7, с. 20]

- осуществление педагогами рефлексии своих личностных качеств и результатов формирования компетенций через самооценку;

- использование активных и интерактивных форм при реализации образовательных программ;

- разработку программно-методического обеспечения процесса формирования профессиональных компетенций;

- $\quad$ корректирование процесса формирования профессиональных компетенций на основе комплексной диагностики.

Профессиональные компетенции формируются не только в образовательном процессе, но и за его пределами: при выполнении практической деятельности, участии во внеучебной работе, научно-исследовательских и творческих проектах. То есть процесс формирования имеет сквозной, междисциплинарный, надпредметный характер. В связи с этим содержание исследуемого процесса в модели представлено через интеграциювнутридисциплинарную, междисциплинарную, трансдисциплинарную. Наше видение такого содержания основывается на идее максимально полного использования всех имеющихся ресурсов образовательной среды, каждый компонент которой непрерывно и систематично «работает» на достижение цели - сформировать высокий уровень профессиональных компетенций у педагогов сельской школы. 
К необходимым организационно-педагогическим условиям формирования профессиональных компетенций педагогов сельской школы относятся следующие: [8, c. 30]

- обеспечение внутридисциплинарной интеграции, в основе которой лежит дифференциация учебного материала, усиление взаимосвязи между его теоретическим и практическим содержанием, учет преемственности ЗУНов, выделение профессионального контекста (сфера сельского образования) в содержании дисциплины;

- обеспечение междисциплинарной интеграции, основанной на согласовании дисциплин/модулей по всем компонентам процесса обучения (цели, содержание, методы, результаты обучения);

- обеспечение трансдисциплинарной интеграции, основанной на использовании различных видов деятельности образовательного процесса (внеурочная деятельность, производственные практики, научно-исследовательская работа, проектная деятельность педагогов и др.).

При интеграции содержания дисциплин процесс обучения проходит на высоком уровне системности знаний, у будущих педагогов формируется целостная картина мира. Интеграция содержания дисциплин не просто дополняет содержание одной дисциплины знаниями из другой дисциплины, а объединяет их и обеспечивает не узкодисциплинарную подготовку, а деятельностную, формирующую важные профессиональные и личностные компетенции. [11, с. 82]

Большим потенциалом в вопросе формирования профессиональных компетенций может обладать сквозная надпредметная образовательная программа междисциплинарного курса, которая относится к программным документам интегрирующего, междисииплинарного и сквозного характера, обеспечивающим иелостность компетентностно-ориентированной образовательной программы для педагогов сельской школы.

Процесс формирования кластера профессиональных компетенций включает три последовательных этапа:

1. Констатирующий этап - комплекс взаимосвязанных процедур, предшествующих непосредственно самому процессу формирования, который образует: [3, с. 59]

- диагностика уровня сформированности кластера профессиональных компетентностей у будущих педагогов: информационной, исследовательской, коммуникативной, организационно-управленческой, а также самоорганизации и саморазвития. Средства оценивания разработаны для каждой компетенции отдельно с учетом их содержания и особенностей;

- экспертная оценка образовательной программы для педагогов сельской школы на предмет наличия признаков формирования профессиональных компетенций, выявление дефицитов.

2. Формирующий этаn - предполагает реализацию комплекса организационно-педагогических условий. Для реализации первого условия следует обеспечить внутридисциплинарную интеграцию содержания дисциплин. Для этого необходимо структурировать учебный материал дисциплины от общего к частному, усилить взаимосвязи между теоретическим и практическим содержанием материала; учесть преемственность знаний и умений со знаниями и умениями других дисциплин; выделить профессиональный контекст педагога сельской школы в содержании дисциплины. Результатом достижения уровня внутридисциплинарной интеграции является возможность использовать потенциал каждой дисциплины по формированию профессиональных компетенций у студентов. Далее следует уровень междисциплинарной интеграции, который предполагает установление междисциплинарных связей между дисциплинами/модулями, обеспечение преемственности содержания между ними, согласование всех компонентов процесса обучения: его цели, содержания, методов, технологий и результатов. Следующее условие - трансдисциплинарная интеграция - основывается на использовании различных видов деятельности в учебно-воспитательном процессе (внеурочная деятельность, производственные практики и научно-исследовательская работа студентов) и предполагает выход за пределы изучения дисциплин, привлечение широких возможностей внеаудиторной работы обучающихся, использование потенциала всех компонентов образовательной среды организации.

3. Оченочный этаn - предполагает проведение повторной диагностики уровня сформированности профессиональных компетенций с использованием всего комплекса методик. На основе полученных данных необходимо проделать сравнительно-сопоставительную рефлексию, сделать выводы и скорректировать дальнейшую работу.

Оценочно-результативный блок модели обращает внимание на результат процесса формирования, заданный как сформированность профессиональных компетенций у будущих педагогов, который позволит им достигать профессиональных результатов в своей профессиональной педагогической деятельности, формируя метапредметные компетенции у обучающихся.

Для того, чтобы осуществить оценочно-результативную работу процесса формирования профессиональных компетенций, необходимо выделить структурные компоненты, критерии и показатели измерения компетенций, уровни их сформированности. [10, с. 63] 
Критерии и показатели сформированности профессиональных компетенций опираются на содержательное наполнение структуры компетенций.

Так, когнитивный критерий включает метазнания и представления об информационной, исследовательской, коммуникативной, организационно-управленческой деятельности педагога сельской школы и его деятельности по самоорганизации и саморазвитию.

Поведенческий критерий предполагает умение экстраполировать метазнания на решение широкого спектра профессиональных задач в сфере ДОД, связанных с информационной, исследовательской, коммуникативной, организационно-управленческой деятельностью педагога сельской школы и деятельностью по самоорганизации и саморазвитию.

Мотивационно-ценностный критерий связан с пониманием важности обладания профессиональными компетенциями и стремлением достигать профессиональных результатов в работе педагогом ДоД.

Таким образом, представленная модель процесса формирования профессиональных компетенций у педагогов сельской школы обладает теоретическим, научным, методологическим обоснованием, на которое можно опираться, при проведении практических мероприятий.

\section{ЛИТЕРАТУРА}

1. Аббасова Л.И., Бутвина 0.Ю., Поликультурная образовательная среда высший школы как фактор формирования профессиональной компетентности педагогов // Современное педагогическое образование. 2020. №3. - С. 44.

2. Ансимова Н.П. Метапредметные образовательные результаты школьни ᄀков как основа формирования универсальных компетенций студентов / Н.П. Ансимова, 0.А. Беляева. // Ярославский педагогический вестник. - 2018. - № 5. - С. 70.

3. Ансимова Н.П. Преемственность образовательных результатов среднего общего и высшего образования / Н.П. Ансимова // Ярославский психологический вестник. - 2019. - № 2 (44). - С. 59.

4. Гинзбург Д.А. Формирование экспертных компетенций и подготовка экспертов в сфере образования // Современное педагогическое образование. 2019. №8. - C. 83.

5. Гущина Т.Н. Технология индивидуализации образовательного процесса в педагогическом вузе / Т.Н. Гущина. - Текст: непосредственный // Инновации в образовании. - 2019. - № 4. - С. 88.

6. Данилова Н.Ю., Формирование профессиональных компетенций студентов - будущих педагогов в области лингвистического образования младших школьников // Вестник ЛГУ им. А.С. Пушкина. 2020. №2. - С. 33.

7. Иванова Л.В., Компетенция самосовершенствования педагога: некоторые аспекты изучения и формирования // Гаудеамус. 2020. №1 (43). - С. 20.

8. Ислямова Э.А., Проведение опытно-экспериментальной проверки формирования предметно-практических компетенций будущих педагогов профессионального обучения по компонентам // Современное педагогическое образование. 2020. №3. - С. 30.

9. К Котько Е.Л. Сущностная характеристика системы педагогических метазнаний / Е.Л. Котько. - Текст: непосредственный // Вестник БарГУ. - 2018. -№ 6. C. 49 .

10. Панасенкова М.М. Формирование профессиональных компетенций учителя в системе дополнительного профессионального образования // Инновационная наука. 2019. №12. - С. 63.

11. Садыкова Т.Н. Способы формирования и оценивания профессиональной компетентности педагога // Вестник ЮУрГГПУ. 2020 . №6 (159). - С. 82.

12. Формирование профессиональных компетентностей педагога средствами дополнительного профессионального образования: учебно-методическое пособие / Институт развития образования; научная редакция А.В. Золотаревой. - Ярославль: ИРО, 2019. - С. 22.

13. Шварева Л.В., Алёшина Е.Ю., Шибанова Е.А., Экспертная оценка как ключевой элемент в формировании профессиональных компетенций будущего педагога // Проблемы современного педагогического образования. 2020. №68-4. - С. 51.

14. Шкерина Л.В., Шкерина Т.А., Дидактические потенциал междисциплинарных учебных модулей в формировании профессиональных компетенций будущих магистров-педагогов // Вестник КГПУ им. В.П. Астафьева. 2019. №1 (47). - С. 39. 